\title{
Differentiation of Spanish brandies according to their metal content
}

\author{
A.M. Cameán ${ }^{\mathrm{a}, *}$, I. Moreno ${ }^{\mathrm{a}}$, M. López-Artíguez $^{\mathrm{b}}$, M. Repetto $^{\mathrm{b}}$, \\ A.G. González ${ }^{\text {c }}$ \\ a Departamento de Bioquímica, Bromatología, Toxicología y Medicina Legal, Universidad de Sevilla, 41012 Sevilla, Spain \\ ${ }^{\mathrm{b}}$ Departamento Regional de Sevilla, Instituto Nacional de Toxicología, PO Box 863, 41080 Sevilla, Spain \\ ${ }^{\mathrm{c}}$ Departamento de Quimica Analitica, Universidad de Sevilla, 41012 Sevilla, Spain
}

Received 6 July 2000; received in revised form 11 October 2000; accepted 12 October 2000

\begin{abstract}
Eleven metals, namely, aluminium, calcium, cadmium, copper, iron, lead, magnesium, manganese, potassium, sodium and zinc were determined in twenty samples of Sherry brandies and twelve samples of Penedés brandies by applying atomic spectrometry techniques. Flame atomic absorption spectrometry was used for quantitating calcium, copper, iron, magnesium, manganese and zinc; atomic emission spectrometry to determine potassium and sodium; and graphite furnace atomic absorption spectrometry to analyse aluminium, cadmium and lead. A chemometric approach was followed to study the discrimination between brandies from Sherry or Penedés according to the metal profile. (C) 2001 Elsevier Science B.V. All rights reserved.
\end{abstract}

Keywords: Brandies; Metal determination; Classification

\section{Introduction}

According to the Spanish regulations, brandy is defined [1] as a complex spirituous beverage, issued from wine distillates, and maturated in oak casks at the adequate environmental conditions for a suitable period of time in order to achieve the organoleptic features peculiar to the elaboration process.

\footnotetext{
* Corresponding author. Tel.: + 34-5-4556762; fax: + 34-54233765.

E-mail address: camean@fafar.us.es (A.M. Cameán).
}

Sherry brandy is elaborated from quality wines $(12-13 \% \mathrm{v} / \mathrm{v}$ ethanol) coming from stocks of varieties Airen Blanca and Palomino. A previous distillation of these wines yields the called holandas which are then aged according to the Solera system of Jerez using as containers oak casks previously employed to maturate Sherry wines. After a period of time within 5-25 years, the resulting product is the Sherry brandy, with alcoholic contents ranging $37-45 \% \mathrm{v} / \mathrm{v}$ ethanol. The aging of Sherry brandies must be carried out necessarily in warehouses located within the triangle whose corners are the cities of Jerez de La Frontera, El Puerto de Santa María and Sanlúcar de Bar- 
Table 1

Experimental conditions for the determination of mineral elements

\begin{tabular}{llll}
\hline Element & Wavelength $(\mathrm{nm})$ & Linear range $\left(\mathrm{mg}^{-1}\right)$ & Dilution range $(\mathrm{v} / \mathrm{v})^{\mathrm{a}}$ \\
\hline $\mathrm{Al}$ & 309.3 & $0.002-0.150$ & Up to $1 / 10$ \\
$\mathrm{Ca}$ & 422.7 & $0.3-5.0$ & Up to $1 / 100$ \\
$\mathrm{Cd}$ & 228.8 & $0.0002-0.0100$ & No dilution \\
$\mathrm{Cu}$ & 324.8 & $0.08-0.50$ & No dilution \\
$\mathrm{Fe}$ & 278.3 & $0.25-0.50$ & No dilution \\
$\mathrm{K}$ & 766.5 & $0.078-$ & Up to $1 / 100$ \\
$\mathrm{Mg}$ & 285.2 & $0.07-0.50$ & Up to $1 / 100$ \\
$\mathrm{Mn}$ & 279.5 & $0.02-2.00$ & No dilution \\
$\mathrm{Na}$ & 589.0 & $0.14-$ & Up to $1 / 500$ \\
$\mathrm{~Pb}$ & 283.3 & $0.0005-0.0100$ & $1 / 3$ \\
$\mathrm{Zn}$ & 213.9 & $0.06-1.00$ & No dilution \\
\hline
\end{tabular}

${ }^{\text {a }}$ Diluted with ethanol $40 \% \mathrm{v} / \mathrm{v}$.

rameda. This requirement comes from the capital role played by the micro-climate found in these environments $[2,3]$.

Penedés brandy is elaborated from highly acid white wines with low alcoholic content (7.5-9.5\% $\mathrm{v} / \mathrm{v}$ ethanol) coming from stocks of varieties Parellada, Macabeo and Xarel.lo. The used wines spring from musts obtained from non-exhaustive presses (and accordingly, exhibiting high contents of dissolved solids), are $\mathrm{SO}_{2}$-free and are subjected to a very special temperature controlled, double discontinuous fermentation process [3]. The obtained holandas are then aged according to either the Solera system of Jerez or the static system in the same container. The containers used are charred new oak casks coming from USA or the Limousin Valley (France).

The origin of the source wine as well as the brandy elaboration procedure influence the metal profile of brandies as a consequence of intermediate processes such as fermentation, maturation and aging of wines and the way in which the distillation is performed to obtain the brandy. Pattern recognition of brandies have been carried out by selecting organic trace compounds such as fusel oils $[4,5]$. In the present paper we introduce the use of metal profiles as possible chemical descriptors for the sake of brandies classification. Thus, the evaluation of metal profiles of brandies may be of great importance in order to differentiation between both kind of Spanish brandies.
Accordingly our aim is to evaluate the metal profile of a number of samples of genuine Sherry and Penedés brandies in order to develop rules for differentiating them.

In the former, the method selected for multicomponent (metals) analysis of brandies was inductively coupled plasma-optical emission spectrometry (ICP-OES). However, the high alcohol content of samples precluded the plasma sustenance. Thus, to avoid any time consuming step devoted to alcohol elimination of samples, we switch to single component methods (atomic absorption spectrometry, AAS and atomic emission spectrometry, AES) for determining the metal profiles.

Table 2

HGA 500 graphite furnace parameters used for analysis of $\mathrm{Al}$, $\mathrm{Cd}$ and $\mathrm{Pb}$ in brandies ${ }^{\mathrm{a}}$

\begin{tabular}{lllll}
\hline Step & \multicolumn{2}{l}{ Temperature $\left({ }^{\circ} \mathrm{C}\right)$} & Ramp (s) & Hold (s) \\
\cline { 2 - 3 } & $\mathrm{Al}$ & $\mathrm{Cd}, \mathrm{Pb}$ & & \\
\hline 1 & 80 & 80 & 5 & 15 \\
2 & 100 & 100 & 5 & 15 \\
3 & 600 & 1400 & 5 & 15 \\
4 & 1600 & 2400 & 0 & $3^{\mathrm{b}}$ \\
5 & 2500 & 2500 & 1 & 1 \\
6 & 20 & 20 & 5 & 5 \\
\hline
\end{tabular}

\footnotetext{
a Argon flow rate, $300 \mathrm{ml} \mathrm{min}{ }^{-1}$; injection volume, $20 \mu \mathrm{l}$; spectral bandwith, $0.7 \mathrm{~nm}$.

${ }^{\mathrm{b}}$ Gas stop for reading.
} 
Table 3

Data matrix obtained in the brandies studied ${ }^{\mathrm{a}}$

\begin{tabular}{|c|c|c|c|c|c|c|c|c|c|}
\hline Sample number & Sample code & $\mathrm{Al}$ & $\mathrm{Pb}$ & $\mathrm{Cu}$ & $\mathrm{Fe}$ & $\mathrm{Ca}$ & $\mathrm{Mg}$ & $\mathrm{Na}$ & $\mathrm{K}$ \\
\hline 1 & $\mathrm{~J}$ & 0.58 & 0.061 & 3.11 & 1.06 & 13.2 & 2.83 & 122.3 & 12.71 \\
\hline 2 & $\mathbf{J}$ & 0.18 & 0.022 & 0.70 & 0.40 & 4.0 & 2.15 & 161.8 & 1.53 \\
\hline 3 & $\mathbf{J}$ & 0.09 & 0.039 & 0.46 & 0.40 & 2.5 & 0.80 & 111.5 & 9.37 \\
\hline 4 & $\mathrm{C}$ & 0.25 & 0.052 & 1.32 & 0.56 & 3.7 & 1.88 & 58.5 & 8.91 \\
\hline 5 & $\mathrm{~J}$ & 0.09 & 0.041 & 0.34 & ND & 1.6 & 0.30 & 111.1 & 0.92 \\
\hline 6 & $\mathrm{C}$ & 0.47 & 0.103 & 1.16 & ND & 3.3 & 0.71 & 48.0 & 8.54 \\
\hline 7 & $\mathrm{~J}$ & 1.14 & 0.313 & 2.59 & 1.78 & 14.8 & 7.99 & 419.9 & 31.20 \\
\hline 8 & $\mathrm{C}$ & 0.16 & 0.050 & 1.32 & 0.70 & 1.0 & 0.24 & 106.0 & 7.68 \\
\hline 9 & $\mathbf{J}$ & 0.19 & 0.034 & 0.88 & 0.54 & 7.9 & 4.14 & 105.0 & 3.69 \\
\hline 10 & $\mathbf{J}$ & 0.38 & 0.224 & 1.46 & 0.81 & 13.4 & 0.18 & 78.9 & 27.30 \\
\hline 11 & $\mathrm{C}$ & 0.31 & 0.073 & 1.95 & 0.43 & 3.3 & 3.40 & 79.5 & 5.78 \\
\hline 12 & $\mathrm{C}$ & 0.24 & 0.035 & 1.83 & 0.34 & 3.4 & 1.39 & 86.5 & 3.57 \\
\hline 13 & $\mathrm{C}$ & 0.33 & 0.020 & 1.34 & 0.73 & 0.3 & 0.08 & 117.6 & 2.20 \\
\hline 14 & $\mathrm{C}$ & 0.21 & 0.071 & 0.94 & 0.48 & 0.3 & 0.06 & 93.3 & 1.14 \\
\hline 15 & $\mathrm{C}$ & 1.58 & 0.070 & 1.02 & 0.70 & 1,0 & 0.20 & 105.1 & 1.25 \\
\hline 16 & $\mathrm{~J}$ & 0.20 & 0.042 & 1.40 & 0.48 & 4.2 & 0.73 & 127.7 & 3.56 \\
\hline 17 & $\mathbf{J}$ & 0.16 & 0.059 & 1.44 & 0.44 & 3.5 & 0.46 & 134.5 & 3.00 \\
\hline 18 & $\mathbf{J}$ & 0.15 & 0.024 & 0.30 & 0.40 & 3.4 & 2.44 & 635.0 & 5.78 \\
\hline 19 & $\mathbf{J}$ & 0.21 & 0.044 & 1.10 & ND & 4.1 & 1.25 & 26.4 & 8.50 \\
\hline 20 & $\mathbf{J}$ & 1.37 & 0.073 & 5.31 & 2.03 & 13.9 & 11.20 & 224.2 & 50.38 \\
\hline 21 & $\mathbf{J}$ & 0.02 & 0.040 & 0.36 & 0.32 & 0.8 & 0.19 & 17.8 & 0.11 \\
\hline 22 & $\mathrm{C}$ & 0.24 & 0.050 & 1.37 & 0.75 & 3.5 & 1.51 & 338.5 & 11.43 \\
\hline 23 & $\mathrm{C}$ & 0.23 & 0.025 & 1.62 & 0.36 & 0.9 & 0.24 & 227.8 & 6.86 \\
\hline 24 & $\mathrm{C}$ & 0.32 & 0.035 & 0.59 & 0.81 & 2.3 & 0.39 & 263.6 & 7.49 \\
\hline 25 & $\mathrm{C}$ & 0.27 & 0.070 & 2.85 & 0.35 & 2.7 & 2.25 & 246.7 & 17.69 \\
\hline 26 & $\mathrm{~J}$ & 0.80 & 0.029 & 2.46 & 1.20 & 9.1 & 2.56 & 83.9 & 37.35 \\
\hline 27 & $\mathbf{J}$ & 0.20 & 0.026 & 0.22 & ND & 3.6 & 0.69 & 38.2 & 7.74 \\
\hline 28 & $\mathbf{J}$ & 1.00 & 0.026 & 0.80 & 0.71 & ND & 2.80 & 141.1 & 38.52 \\
\hline 29 & $\mathbf{J}$ & 1.00 & 0.015 & 0.58 & 0.80 & ND & 1.41 & 249.4 & 7.31 \\
\hline 30 & $\mathbf{J}$ & 0.50 & 0.008 & 1.62 & ND & 1.7 & 0.33 & 43.9 & 6.28 \\
\hline 31 & $\mathbf{J}$ & 0.80 & 0.018 & 1.77 & 0.62 & ND & 2.24 & 60.6 & 70.06 \\
\hline 32 & $\mathrm{~J}$ & 0.30 & 0.022 & 1.19 & ND & 3.3 & 0.57 & 43.0 & 5.23 \\
\hline
\end{tabular}

${ }^{a}$ Metal concentrations expressed as mg per 1 of brandy.

\section{Materials and methods}

\subsection{Apparatus}

A Perkin Elmer 3100 (Perkin Elmer Corp., Norwalk, CT) atomic absorption spectrometer was used to quantitate calcium, copper, iron, magnesium, manganese and zinc by using flame atomic absorption spectrometry (FAAS) and potassium and sodium by AES. A Perkin Elmer 1100B atomic absorption spectrometer fitted to a Perkin Elmer HG-500 graphite furnace and a Perkin Elmer AS-40 automatic injector was em- ployed to determine aluminium, cadmium and lead by the technique of graphite furnace atomic absorption spectrometry (GFAAS). Experimental conditions for metal determination are gathered in Table 1. GFAAS temperature programs for determining aluminium, cadmium and lead are presented in Table 2.

\subsection{Reagents and solutions}

Aluminium metal, calcium carbonate, cadmium metal, copper metal, iron wire, lead metal, magnesium ribbon, manganese metal, potassium chlo- 
ride, sodium chloride and zinc metal of analytical reagent grade (E. Merck, Darmstadt, Germany) were used for preparing stock solutions of $\sim 1000$ mg $1^{-1}$ following the Perkin Elmer guidelines. Remainder reagents were of reagent grade or better. Milli-Q treated water (Millipore Corp., Bedford, MA) was used throughout. The working solutions were prepared by suitable dilution from the corresponding stock solutions with $40 \% \mathrm{v} / \mathrm{v}$ ethanolic solution.

\subsection{Samples}

Twenty samples of Sherry brandies with D.O. trademark and twelve of Penedés brandies were purchased in liquor retails and markets. These samples correspond to the brands most commonly consumed in Spain. The alcoholic degree ranged within $35-40 \% \mathrm{v} / \mathrm{v}$ ethanol. Once opened, the bottles were capped with our own corks and were stored in a cupboard at room temperature. Three

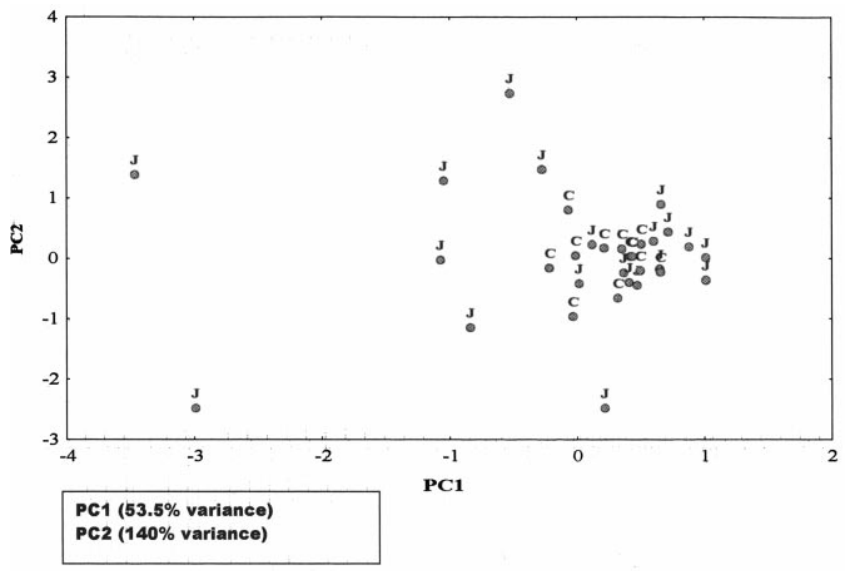

Fig. 1. Scores plot of the studied cases for the two first PCs. Labels $\mathbf{J}$ and $\mathrm{C}$ refer to Sherry and Penedés brandy samples, respectively.

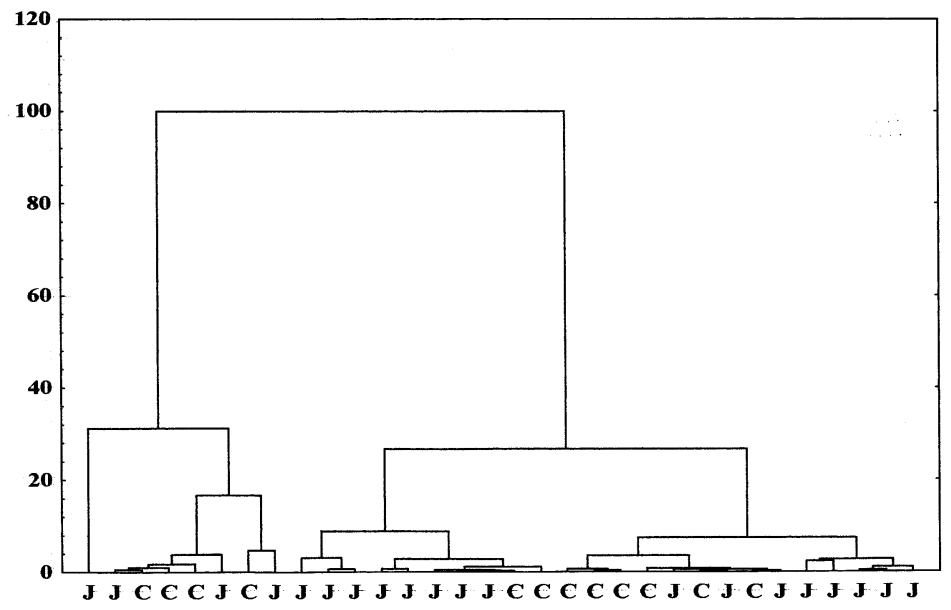

Fig. 2. Dendrogram for the studied cases following the Ward's method for cluster amalgamation and euclidean distance for linkage. Labels $\mathbf{J}$ and $\mathbf{C}$ refer to Sherry and Penedés brandy samples, respectively. 


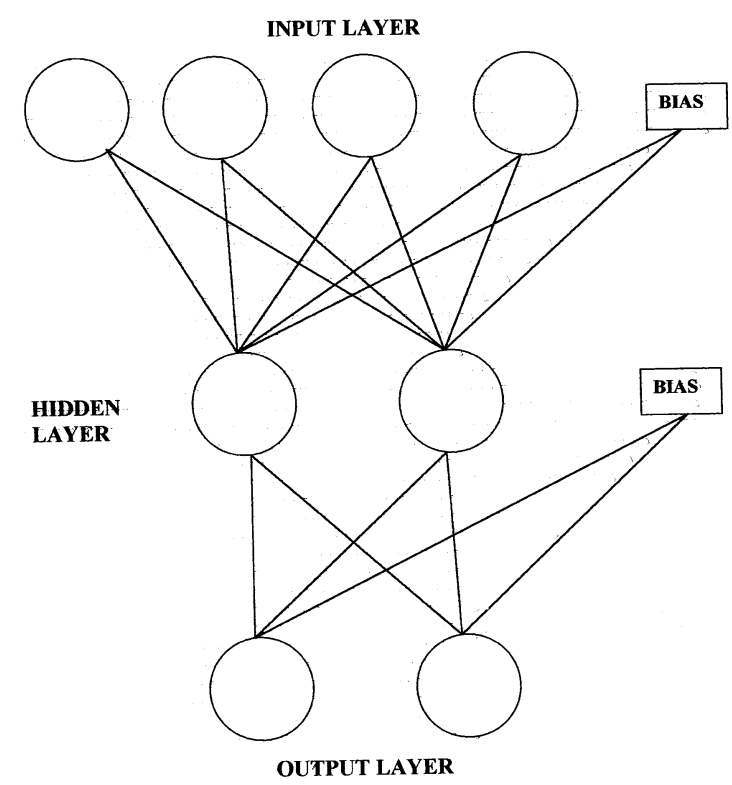

Fig. 3. Architecture of the BPNN: $4 \times 2 \times 2$ plus bias. Four metal descriptors for the input layer ( $\mathrm{Ca}, \mathrm{Fe}, \mathrm{Cu}$ and $\mathrm{Mg}$ ), a hidden layer of two nodes (empirically established) and a output layer with two nodes (the two categories $\mathrm{J}$ and $\mathrm{C}$ )

containers from different lots of each purchased sample were analysed separately. Aliquots of brandies were used without prior treatments for preparing the assay solutions to be analysed. These assay solutions were the pure liquor for the determination of copper, iron, manganese and zinc. Otherwise, suitable dilutions with $40 \%$ $\mathrm{v} / \mathrm{v}$ ethanolic solution were performed as indicated in Table 1.

\subsection{Analytical procedures}

Brandies were diluted as appropriate for obtaining suitable read-outs for proper quantitations. $\mathrm{Ca}, \mathrm{Cu}, \mathrm{Fe}, \mathrm{Mg}, \mathrm{Mn}$ and $\mathrm{Zn}$ were determined by FAAS; $\mathrm{Na}$ and $\mathrm{K}$, by AES and $\mathrm{Al}, \mathrm{Cd}$ and $\mathrm{Pb}$ by GFAAS. Sample dilution ranges for each element were already given in Table 1 and the temperature programs for the GFAAS determinations were indicated in Table 2. Linear concentration intervals for each element range between the detection limit (in concentration units) and a value, which is less or equal to the maximal concentration, recom- mended in the Perkin Elmer guidelines. All elements with the exception of As, were determined from external calibration, by matching the alcoholic content in the samples and the standards used in calibration.

\section{Results and discussion}

The metal content of the different brandies was determined and carefully scrutinised. Each sample was identified with a code indicating their origin (J: Jerez (Sherry) brandy or C: Catalonian (Penedés) brandy). All the results were expressed in $\mathrm{mg}$ of metal per litre of brandy, as the average of triplicate measurements. These results were rounded up to the last significant figure associated with random error.

Initial data analysis encompasses a variety of techniques focused to explore the quality of the descriptors chosen to characterise the studied samples [6]. Irrelevant descriptors are the most expensive ones because they only contribute to darken the information contained in the data. Thus they should be picked out from the data matrix to ensure unbiased findings.

Features $\mathrm{Zn}, \mathrm{Cd}$ and $\mathrm{Mn}$ exhibited high number of not detected cases. Thus, it should be advisable to reject them in order to avoid misleading conclusions. In such a way, the data matrix once these three descriptors were eliminated has dimensions $32 \times 8$. This is shown in Table 3 .

Aside from its value for eliminating irrespective variables, feature selection is a very important step for the sake of classification. If the number of patterns or samples is $n$, and the dimension of the pattern space is $d$, the minimum requirement to be fulfilled to achieve a correct class separation is $n / d>3$ [7]. In our case, the ratio samples/descriptors is four, addressing the requirement.

A straightforward way to acquaint the discriminant efficiency of the variables is the use of categorised box and whisker plots [6]. By considering both the median and the interquartil range of each remaining variable for every class, the most differentiating descriptors were $\mathrm{Ca}, \mathrm{Fe}, \mathrm{Cu}$ and $\mathrm{Mg}$. 
On the other hand PCA-based display methods were also considered. [8] The data matrix was subjected to PCA leading to four principal components (PCs) which explain about the $87 \%$ of the data variance, with communalities higher than 0.7 always. The most significant variables will correspond to those descriptors with higher PC-loadings. In our case, they were $\mathrm{Fe}, \mathrm{Mg}, \mathrm{Cu}$ and $\mathrm{Ca}$ in very good agreement with the previous non-parametric assay. Scores plots of the two first PCs issued from PCA may be of interest to visualize data trends. The corresponding scores plot for the studied brandies is shown in Fig. 1. As a first glance, it may be considered that the Sherry samples are surrounding the Penedés ones. In consequence, a linear separation of the classes based on their origin was not found. Thus, linear classification pattern recognition techniques cannot be of interest for this case.

To assess this preliminary study, unsupervised pattern recognition methods were applied. Data matrix was subjected to an agglomerative hierarchical cluster analysis of samples [9]. Taking the euclidean distance as similarity measure and the Ward method as amalgamation rule, the dendrogram of Fig. 2 was obtained. As can be seen, no class structure is observed, the samples forming clusters containing both types of brandies.

\section{Supervised pattern recognition using neural networks based algorithms}

Majority of parametric pattern recognition classification methods (LDA, SIMCA, PLS-DA) $[4,10]$ works well when the classes present inner similarities and are well separated from each other (minimization of the ratio of within classes sum of squares and between classes sum of squares). Thus, when dealing with data exhibiting non-linear class structure, these methods are not a good choice; it should be more advisable to call on neural networks classification algorithms like the multilayer perceptron networks trained by error back propagation (MPN-BP) [11-13]. They are the tools of the trade when dealing with highly non-linear frontiers between classes because the use of sigmoidal or hyperbolic tangent functions as transfer functions in the nodes associated to hidden and output layers. Based on a preliminary study, MPN-BP was performed with the following architecture: four input nodes (the $\mathrm{Fe}, \mathrm{Mn}, \mathrm{Cu}$ and $\mathrm{Ca}$ descriptor values) plus bias in the inactive input layer, two output nodes (the two classes) for the output layer, and one hidden layer containing two nodes. The corresponding schema can be seen in Fig. 3. Input values were normalized within -1 and 1 . Outputs were normalized within $0-1$. Initial weights were normalized between -0.1 and 0.1 . The target error was set to 0.15 . The sigmoidal function was chosen as transfer function. The training rate was set to $\eta=0.2$ and the momentum to $\eta=0.5$. For validation purposes the studied data set was randomly divided into a calibration set and a validation set, each considering the $50 \%$ of the samples of every class. To suitably validate the recalling ability (\%hits in classifying the calibration set) and the prediction performance $(\%$ hits in classifying the validation set), both sets were repeated ten times for different constitutions. The output is processed in the following way: for values higher than 0.8 the value 1 (hit) is taken and otherwise the value 0 (fail) is produced. The recalling average performance was of $100 \%$, once sample no. 6 was removed as an outlier, and the prediction average performance was of $93 \%$.

Following the literature another validation procedure leading to a better estimation of the expected reliability of the network model is the leave-one-out [4] or cross-validation procedure; that is, leaving out of the training set each time, a different sample and testing the model with the sample left out from the training. Doing this, the percentage hits in predicting the 'one-member test set' was of about $81 \%$, a fair value for the prediction ability.

Accordingly, MPN-BP enables the suitable discrimination of Sherry and Penedés samples using $\mathrm{Fe}, \mathrm{Mg}, \mathrm{Cu}$ and $\mathrm{Ca}$ as descriptors.

\section{Conclusion}

The metal profile of brandies seems to be very sensible to the elaboration process. Accordingly, 
metals content has been selected as chemical descriptors for classifying two different kinds of Spanish brandies: Sherry and Penedés brandies. The use of classification procedures based on artificial neural networks leads to about $90 \%$ hits in prediction ability.

\section{References}

[1] Real Decreto 2484/74, Alcohol y bebidas alcohólicas. Reglamentación para elaboración, circulación y comercio del Brandy. Boletín Oficial del Estado de 11 de Septiembre, , 1974.

[2] Ministerio de Agricultura, Pesca y Alimentación (MAPA), Orden de 31 de Mayo de 1989 por la que se ratifica el Reglamento de la Denominación Específica 'Brandy de Jerez' y de su Consejo Regulador. Boletín Oficial del Estado, vol. 142, 1989, pp. 1839118396.
[3] J. Muñoz Ramos, Enciclopedia de los Alcoholes, Planeta, Madrid, 1996.

[4] R. Henrion, G. Henrion, Multivariate Datenanalyse, Springer-Verlag, Heidelberg, 1995.

[5] R. Henrion, G. Henrion, G Michael, D. Petereit, Zeitschirft für Chemie 28 (1988) 315-324.

[6] J.C. Miller, J.N. Miller, Statistics for Analytical Chemistry, Ellis Horwood PTR Prentice Hall, Chichester, 1993.

[7] K. Varmuza, Pattern Recognition in Chemistry, Springer Verlag, Heidelberg, 1980.

[8] C. Chatfield, A.J. Collins, Introduction to Multivariate Analysis, Chapman and Hall, London, 1980.

[9] D.L. Massart, L. Kauffmann, Interpretation of Chemical Data by use of Cluster Analysis, Wiley, New York, 1983.

[10] D. González-Arjona, G. López-Pérez, A.G. González, Talanta 49 (1999) 189-197.

[11] J. Zupan, J. Gasteiger, Neural Networks for Chemists, VCH, Weinheim, 1993.

[12] J.R. Lang, H.T. Mayfield, M.V. Henly, P.R. Kromann, Anal. Chem. 63 (1991) 1256.

[13] M.C.G. Parrilla, A.G. González, F.J. Heredia, A.M. Troncoso, J. Agric. Food Chem. 45 (1997) 3487. 